\title{
Review Paper on Development of Polymer Composite Material and its Characterisation
}

\author{
V. B. Ugale ${ }^{1}$, K. K. Singh ${ }^{2}$, Prashant Kumar ${ }^{3}$ \\ ${ }^{1}$ (Department of Mechanical Engineering, College of Military Engineering, Pune, India) \\ ${ }^{2}$ (Department of Mechanical Engineering, Indian School of Mines, Dhanbad, India) \\ ${ }^{3}$ (Department of Mechanical Engineering, College of Engineering, Pune, India)
}

\begin{abstract}
The present study is an attempt to take an overview of the work done in the area of characterization of polymer composite materials, different constituent materials used in polymer composites, failure mechanism and manufacturing process of polymer composite. Based on comprehensive literature review of various aspects in developing polymer composite materials, it is observed that extensive work has been done related to monocoque structure and thick polymer sandwich panels, whereas studies carried out to analyse static and dynamic strength of thin polymer sandwich panels are limited. The behaviour under flexural loading and impact loading, and interlaminar fracture toughness of laminated polymer composite are the main areas of interest of researchers.
\end{abstract}

Keywords - Sandwich panel, Monocoque structure, Impact loading, Delamination, Flexural strength

\section{INTRODUCTION}

Polymer composites are nowadays widely used in aerospace vehicles, automobiles, marine, sports equipments, windmills, building, consumer industries for their excellent properties like lightweight, high stiffness, high strength, good corrosion resistance, excellent design flexibility, less prone to environmental degradation, excellent thermal insulation, acoustic damping and good aesthetic features. Polymer composite materials are usually used in the form of monocoque structures. The monocoque structure is heavy, expensive and the laminas of the middle portion, close to the neutral plane of the structure, are not used to their full strength under flexural loading. To overcome these limitations of the monocoque structures, sandwich- structures are being developed. The sandwich- structures are relatively lighter in weight and less expensive. Objective is to carry out the literature review related to characterization of polymer composite materials, different materials used in polymer composites, failure mechanism, manufacturing process of polymer composite etc. which will be helpful to develop thin polymer sandwich panel suitable for preparing the outer cover or outer body of various machines and appliances.

\section{LITERATURE REVIEW}

\subsection{Monocoque Structure}

Many researchers worked on behavior of monocoque structure [1-8]. C. Wonderly et al [1] studied the mechanical properties of monocoque structure of glass fibers and carbon fibers under variety of loading conditions. The carbon fibers laminates proved mechanically superior under loading conditions where the strength is mainly fiber dominated, i. e. under tensile loading and indentation. The glass fiber laminates were equally strong or stronger under loading conditions where the strength is mainly resin dominated, i.e. compressive loading and ballistic impact. Both composites exhibit excellent properties and are suitable for use in large ships. Carbon fiber ship could be built significantly lighter than glass fiber ditto of the same strength and/or stiffness. G. Caprino et al. [2] observed the influence of material thickness on response of monocoque structure of carbon fabric/epoxy under low velocity impact. R. Tiberkak et al [3] invested the behavior of fiber reinforced composite plates subjected to low velocity impact by finite element analysis. Mindlin's plate theory was implemented into the FE approach in which a 9 node lagrangian element was considered. The laminates with different stacking sequence were analysed at different impact velocities. As the laminate structure is susceptible to delamination under impact loading [4], some data related to overall damage area of monocoque structure under impact loading is presented. The overall damage area of monocoque structure made of carbon fibers is shown in Fig. 1. Lopez [5] used CFRP laminate of $1.6 \mathrm{~mm}$ thickness made of eight layers of plain woven AGP-193-PW/8552 (AS4 fiber) and Kumar [6] used CFRP laminates having nominal thickness of $3 \mathrm{~mm}$ for the impact analysis under air gun set up. Cantwell [7] analysed $2 \mathrm{~mm}$ thick CFRP laminate manufactured from $\left( \pm 45^{0}\right)$ sheets of pre-impregnated Grafil XA-S fibers in Ciba-Geigy BSL 914C epoxy under drop weight impact test set up. G. Dorey, et al. [8]. carried out the study of carbon fiber, Kevlar 49 fiber and carbon 
fiber/Kevlar 49 fiber hybrid reinforced epoxy laminates, comprising $0^{\circ}, 90^{\circ}$ and $45^{\circ}$ layers, were subjected to drop weight and ball gun impact at incident energies upto 18J. It was observed that a hybrid composite can have significantly better overall impact properties than laminates reinforced with only one type of fiber.

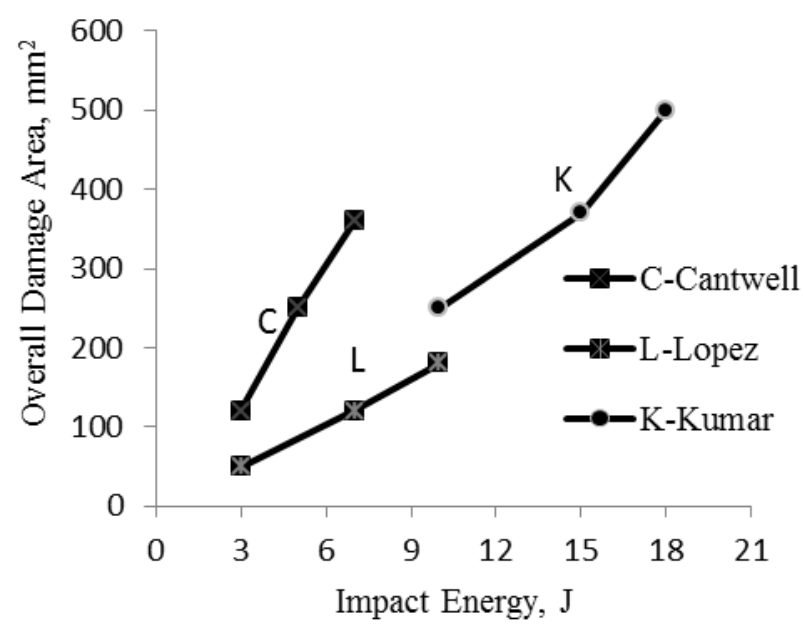

Fig. 1 Overall damage area in monocoque FRP laminate

\subsection{Sandwich Structure}

Much of the earlier work focused on the behavior of honeycomb core sandwich structures under low velocity impact [9-17]. Usually honeycomb cores are made out of aluminium or out of composite materials: Nomex, glass thermoplastic or glass phenolic. One of the problems in the honeycomb sandwich structures is the low surface area of core for bonding. D. Jiang et al. [15] analysed thick FRP honeycomb panel under low velocity impact loading. By inserting an additional inter sheet in the core reduces the local crash/buckling. P. Qiao et al. [16] concerned with impact analysis of a FRP Honeycomb sandwich panel with sinusoidal core geometry in the plane and extending vertically between face laminates. The impact responses (e. g., contact force and central deflection) are predicted by softwares ABAQUS and LS-DYNA. J. H. Park et al. [17] studied the damage resistance of sandwich structure composed of Nomex honeycomb core (thickness $10 \mathrm{~mm}$ and 20 $\mathrm{mm}$ ) and two kinds of face sheets (carbon / epoxy and glass/ epoxy laminates) subjected to low velocity impact. The impact resistance of the sandwich panel is greatly influenced by the face sheet type and core thickness. The impact damages are mainly delamination in the face sheets.

Also some of the investigators studied the flexural strength, stiffness of the sandwich structures made of honeycomb core [18, 19]. J. F. Davalos et al. [18] analysed thick FRP honeycomb panel for bridge decks under three point bend and four point bent test. Haibin Ning \& Gregg M. Janowski et al. [19] designed, analysed and manufactured a mass transit bus side body panel using thermoplasic composite materials consisting of Eglass fiber/polypropylene face sheets and polypropylene honeycomb core . It provides low weight, high strength, recycling ability and energy absorption benefits. Weeks and Sun [20] considered the construction of multiple honeycomb core layers and additional reinforcing sheets. This construction provided better impact resistance and higher residual strength than traditional construction.

The other most commonly used core material is foams. One of the advantages of foam cores is the increased support surface for bonding with face sheets. The response of foam core sandwich constructions is studied by many investigators [21-26]. The response of foam core sandwich composites depends on density and modulus of foam [23, 24]. Shear fracture was found to occur in PVC/PUR system based brittle core materials. In contrast, buckling failures in the uppermost composite skin were observed in the intermediate modulus system, whereas initial damage in the higher modulus PVC/PUR systems took the form of delamination within the top surface skin. J. L. Yu et al. [27] analysed thick sandwich beams made of closed cell aluminium foam in three point bending and low velocity impact. K. Imielinska et al. [28] investigated effect of manufacturing on impact damage behavior in typical marine composites of E-glass fiber/polyester/PVC foam core sandwich structures. Face/core bonding was performed using two different adhesives and the matrix resin. Wet layup process is superior to adhesive bonding of face to foam. A. Corigliano et al. [29] analysed the sandwich structure made of no of layers of interwoven glass fiber/polymer matrix skin and syntactic foam made by hallow glass micro spheres embedded in an epoxy matrix. Experimental tests and numerical finite element simulations have been performed in order to characterize fully the behavior of this sandwich material for naval applications. Gaudenzi et al. [30] investigated the design and testing of glass fiber sandwich panels for car body constructions. Each 
face of the sandwich panel was a fiber-reinforced laminate of $4 \mathrm{~mm}$ thickness. The glass fabrics were used as reinforcement of composite. Vinyl ester was employed as matrix material mixed with the aluminum trioxide powder (ATH) for improving the fire resistance. The core was polymeric foam, with a thickness of $40 \mathrm{~mm}$; the skins were bonded to the core materials with an epoxy-based adhesive. The failure loads of the composite panel were found out numerically and experimentally both for the laminated skin of the sandwich panel and for the complete structure.

In the recent years, several investigators have considered a number of innovative ideas to improve the impact strength of foam cores [31-36]. Belingardi et al. [31] reported substantial improvement in the dynamic impact restance of sandwich structure by addition of a net of resin walls within the foam. Torre and Kenny[32] reported development of new type of sandwich construction consisted of skins made from glass fiber/phenolic matrix and core formed by internal corrugated structure of the same material as that of skin filled by phenolic foam to improve crashworthiness for transport applications. Vaidya et al. [33-36] studied static compression, low velocity impact, and high strain compression response of a number of innovative sandwich constructions with reinforced cores by means of three dimensional Z-pins embedded in foam, honeycomb cells filled with foam, and hallow space accessible Z-pins acting as core reinforcement to increase transverse stiffness as compared to foam cores.

Hollow core sandwich composite construction is a newly developed concept [36-40]. One of the concepts is truss reinforced core [36-38] and other is an integrated hollow core in which face sheet and core are integrated together in one construction. The fiber perform in integrated core sandwich is three dimensional and consists of two bidirectional woven E- glass fabric surfaces, which are mechanically connected with vertical woven ply. This produces fabric that has preset space between two surface decks. Vaidya et al. [39] studied integral hollow core sandwich composite panels of different types. The various functionalities that were considered in the study included, wax filling, wire routing, adhesively bonded polycarbonate sheet facing, and stacking of two integral cores. The facesheet of integral hallow core sandwich is very thin and week in sustaining low velocity impact loading. M. V. Hosur et al. [40] studied 3-D hollow integrated core composite sandwich laminates with and without additional face sheets were fabricated using vacuum assisted resin infusion molding process in multiple steps. For additional facing, plain weave glass fabric and twill weave carbon fabrics were used on top and bottom sides of the panels in four different monolithic and hybrid combinations. Results of the study indicate that glass facing sustained maximum load followed by glass-carbon hybrid, carbon-glass hybrid, and carbon facings. Scarponi et al. [41] also studied the behavior of thick sandwich panels under impact loading.

N. K. Naik et al. [42] observed that transverse static central load threshold for damage initiation is higher for woven fabric composites compared those of cross ply laminates made of unidirectional layers and unidirectional composites.

Some investigators used natural fibers for making the sandwich panels [43, 44]. A. Dweib et al. [43] analysed composite sandwich beams made of soyabean oil based resin and natural fibers ( flax, cellulose, pulp, recycled paper, chicken feathers) for the roof of house. The flexural strength and stiffness are analysed. K. Sabeel Ahmed et al. [44] studied effect of stacking sequence on tensile, flexural and interlaminar shear properties of untreated woven jute and glass fabric reinforced polyester hybrid composites experimentally. The results indicated that the properties of jute composites can be considerably improved by incorporation of glass fiber as extreme glass plies. The laminates employing jute fabric core are also viable materials as far as cost and strength are concerned $[44,45]$.

Few investigators worked on thin sandwich panels. A Kumar et al. [46] analised thin sandwich panels made of short fiber FRP facesheets and coremat. The properties such as load bearing capacity, stiffness and area density of the thin sandwich panel were compared with thin mild steel sheet. The polyester foam Coremats [46, 47] are available as thin sheets of $1-3 \mathrm{~mm}$ thickness, are very light weight and are easy to use as core material. However, the resin is dispersed through the micro holes of Coremat making core significantly heavier than foam. But Coremat/resin core is much lighter than the corresponding portion of a monocoque laminate.

\section{DISCUSSION}

There are many wide varieties of core materials currently in use. Among them, honeycomb, foam, balsa and corrugated cores are most widely used. One of the major concerns in the use of monolithic and a sandwich composite material is the damage induced in these materials by foreign body impacts that are expected during life of structures. Impact induced damage can cause drastic reduction in strength of the structure. For this reason impact on composite structures has been subject of intense research efforts. Of particular interest is the low velocity impact situation that arises from tool drops, runway debris, hail storms and others. Low velocity foreign object impact on sandwich structures can induce damage to the facings, core material, and the core facing interface [4]. Damage initiation thresholds and damage size depend on the properties of core materials, face sheets, and the relationship between the properties of the cores and those of facings. Woven fabric such as glass 
fabric, carbon fabric or glass fabric/carbon fabric hybrid reinforced with resin is the better material for facesheet of sandwich panel. It is difficult to manufacture thin sandwich panel made of PVC/PUR foam or honeycomb structure. Coremat is the recently developed material suitable for core of thin sandwich panel (thickness close to $3 \mathrm{~mm})[46,47]$. Also jute is viable material for the core of thin panel as far as cost and strength are concerned $[44,45]$. Composites may be manufactured by vacuum assisted resin transfer moulding (Fig. 2) to improve the fiber volume fraction $[28,40]$.

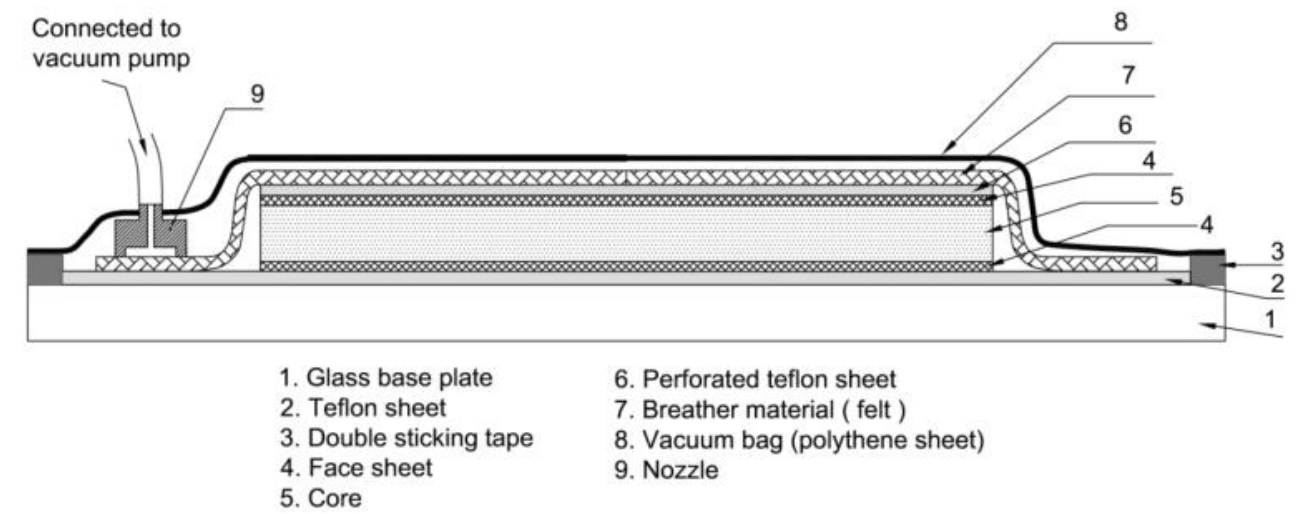

Fig. 2 Vacuum bagging technique

\section{CONCLUSION}

Based on comprehensive literature review of various aspects in developing polymer composite materials, the following conclusions have been drawn.

Extensive work has been done related to monocoque structure and thick polymer sandwich panels; whereas studies carried out to analyse static and dynamic strength of thin polymer sandwich panels are limited. There is scope to develop thin polymer sandwich panels. Laminate structure is susceptible to delamination under impact loading. Delamination is the most ominous in the reduction of the compressive, bending and buckling strengths because the separation of the plies reduces the laminate stiffness. Drop weight impact test of the laminate to be necessary to analyse its behavior under impact loading. Flexural test is also required to analyse the flexural strength, flexural stiffness and to analyse the load verses deflection relation. There is need of interlaminar fracture toughness test to quantify the delamination resistance. Wet layup process and vacuum assisted resin moulding process may be the better process for manufacturing the composite.

\section{REFERENCES}

[1] Wonderly, C., Grenestedt, J., Fernlund, G. and Cepus, E. Comparison of Mechanical Properties of Glass Fiber/Venyl Ester and Carbon Fiber/Venyl Ester Composites, Composites: Part B, 36, 2005, 417-426.

[2] Caprino and Lopresto, V. Influence of Material Thickness on the Response of Carbon Fabric / Epoxy Panels to Low Velocity Impact, Composite Science and Technology, 59, 1999, 2279-2286.

[3] Tiberkak, R., Bachene, M., Rechak, S. and Necib, B. Damage Prediction in Composite Plates Subjected to Low Velocity Impact, Composite Structures, 83, 2008, 73-82.

[4] Abrate, S. Impact on Composite Structures, (Cambridge: Cambridge University Press, 1998).

[5] Lopez-puente, J., Zaera, R., and Navarro, C. The Effect of Low Temperatures on the Intermediate and High Velocity Impact Response of CFRPs, Composites Part B, 33, 2002, 559-566.

[6] Kumar, P., Rai, B. Reduction of Impact Damage in KFRP through Replacement of Surface Plies with Glass Fabric Plies, Composite Materials, 25(4), 1991, 694-702.

[7] Cantwell, W.J. and Morton, J. Comparison of the Low and High Velocity Impact Response of CFRP, Composites, 20, 1989, 545551.

[8] Dorey, G., Sidey, G.R. and Hutchings, J. Impact Properties of Carbon Fibre/ Kevlar 49 Fibre Hybrid Composites, Composites, 1, 1978, 25-32.

[9] Nettles, A. T. and Hodge, A. J. Impact Testing of Glass/Phenolic Honeycomb Panels with Graphit/ Epoxy Facesheet. In: Proceedings of $35^{\text {th }}$ International SAMPE Symposium and Exhibition, Anaheim CA, 35(2-5), 1990, 1430-40.

[10] Kim, C. G. and Jun, E. Impact Resistance of Composite Laminated Sandwich Structures. In: Proceedings of $8^{\text {th }}$ International Conference on Composite Materials (ICCM/8), Honolulu, vol 32, 15-19 July, 1991, p.G1-8.

[11] Kim, C. G. and Jun, E. Impact Resistance of Composite Laminated Sandwich Plates, Compos Mat, 26(15), 1992, $2247-61$.

[12] Palm, T. E. Impact Resistance and Residual Compressive Strength of Composite Sandwich Panels. In: Proceedings of $8^{\text {th }}$ International Conference on Composite Materials ( ICCM/8), Honolulu, Vol 3, 1991, p.G1-13.

[13] Charles, J. P. and Guedra-Degeorges, D. Impact Damage Tolerance of Helicopter Sandwich Structures. In: Proceedings of $23^{\text {th }}$ International SAMPE Conference Kiamesha Lake, NY, 21-24, 1991, 51-61.

[14] Herup, E.W.J. and Palazotto, A. N. Low Velocity Impact Damage Initiation in Graphite/Epoxy/Nomex Honeycomb-Sandwich Plates, Compos Sci Technol, 57, 1997, 1581-98. 
[15] Jiang, D. and Dongwei, S. Local Displacement of Core in Two-Layer Sandwich Composite Structures Subjected to Low Velocity Impact, Composite Structures, 71(1), 2005, 53-60.

[16] Qiao, P. and Yang, M. Impact Analysis of Fibre Reinforced Polymer Honeycomb Composite Sandwich Beams, Composites: Part $B, 38,2007,739-750$.

[17] Park, J. H. and Ha, S. K. Impact Damage Resistance of Sandwich Structure Subjected to Low Velocity Impact, Journal of Materials Processing Technology, 20 I, 2008, 425-430.

[18] Davalos, J. F., Qiao, P., X Frank, Xu., Robinson, J., Karl, E. and Barth. Modelling and Characterization of Fiber-Reinforced Plastic Honeycomb Sandwich Panels for Highway Bridge Applications. Composite Structures 52, 2001, 441-452.

[19] Ning, H., Janowski, G. M., Vaidya, U. K. and Husman, G., Thermoplastic Sandwich Structure Design and Manufacturing for the Body Panel of Mass Transit Vehicle, Composite Structures, 80(1), 2007, 82-91.

[20] Weeks, C. A. and Sun, C. T. Multicore Composite Laminates, Journal of Adv Materials, 1994, 28-37.

[21] Wu, C. L. and Sun, C. T. Low Velocity Impact Damage in Composite Sandwich Beams, Composite Structures, 34, 1996, 21-7.

[22] Hazizan, A. M. and Cantwell, W. J. The Low Velocity Impact Response of Foam Based Sandwich Structures, Composite: Part B: Eng, 33, 2002, 193-204.

[23] Caprino, G. and Teti, R. Impact and Post Impact Behaviour of Foam Core Sandwich Structures. Composite Structure, 29, 1994, 4755.

[24] Abot, J. L. and Daniel, I. M. Composite Sandwich Beams under Low Velocity Impact. In: CD Proc 42 AIAA/ASME/ASCE/AHS/ASCSD Conf, Seattle, WA, 2001, paper no 2001-1186.

[25] Anderson, T. and Madenci, E. Experimental Investigation Low Velocity Impact Characteristics of Sandwich Composites, Composite Structures, 50, 2000, 239-47.

[26] Mines, R. A. W., Worrall, C. M. and Gibson, A. G. Low Velocity Perforation Behaviour of Polymer Composite Sandwich Panels, International Journal of Impact Eng, 21 (10), 1998, 855-79.

[27] Yu, J., Wang, E., Li, J. and Zheng, Z. Static and Low Velocity Impact Behaviour of Sandwich Beams with Closed Cell Aluminium Foam Core in Three Point Bending, International Journal of Impact Engineering, 35, 2008, 885-894.

[28] Imieliska, K., Guillaumat, L., Wojtyra, R. and Castaings, M. Effects of Manufacturing and Face/Core Bonding on Impact Damage in Glass/Polyester-PVC Foam Core Sandwich Panels, Composites: Part B, 39(6), 2008, 1034-1041.

[29] Corigliano, A., Rizzi, E. and Papa, E. Experimental Characterization and Numerical Simulations of a Syntactic-Foam/Glass-Fibre Composite Sandwich, Composite Science and Technology, 60, 2000, 2169-2180.

[30] Gaudenzi, P., Pascucci, A., Barboni, R. and Horoschenkoff, A. Analysis of a Glass-Fibre Sandwich Panel for Car Body Constructions, Composite Structures, 38(1-4), 1997, 421-433.

[31] Belingardi, G., Cavatotra, M. P. and Duella, R. [2003]. Material Charactrization of a Composite Foam Sandwich for the Front Structure of High Speed Train. Composite Structures, 61, 2003, 13-25.

[32] Torre, L. and Kenny, J. M. Impact Testing and Simulation of Composite Sandwich Structures for Civil Transportation, Composite Structures, 50, 2000, 257-67.

[33] Vaidya, U. K., Kamath, M. V., Mahfuz, H. and jeelani, S. Low Velocity Impact Response of Resin Infused Moulded Foam Filled Honeycomb Sandwich Composites, Journal of Reinforced Plastic Composites, 17(9), 1998, 819-49.

[34] Vaidya, U. K., Nelson, S., Sinn, B. and Mathew, B. Processing and High Strain Rate Impact Response of Multifunctional Sandwich Structures, Composite Structures ,52, 2001, 429-40.

[35] Vaidya, U. K., Kumar, P., Hosur, M. V., Kamath, M. V., Mahfuz, H., and Jeelani, S. Low Velocity and High Strain Rate Impact of Pin Reinforced Foam Core Sandwich Structures. In: Newaz G, Gibson R F, editors. Proceedings of the Eighth Japan-US Conference on Composite Materials, 1998, p. 721-9.

[36] Vaidya, U. K., Kamath, M. V., Hosur, M. V., Mahfuz, H. and Jeelani, S. Low Velocity Impact Response of Hallow and Foam Filled Z-pin Reinforced Core, Journal of Composite Technology Res. JCTRER, 21(2), 1999, 84-97.

[37] Freitas, G., Magee, C., Dardzinski, P. and Fusco, T. Fiber Insertion Process for Improved Damage Tolerance in Aircraft Laminates, J Adv Mater, 25(4), 1994,36-43.

Barrett, D. J. A Micromechanical Model for the Analysis of Z- Fiber Reinforcement. In: AIAA/ASCE/ASME/AHS SDM Conference, Salt Lake City, Utah, AIAA-96-1329-CP, 1996, p.62-7.

[39] Vaidya, U. K., Hosur, M. V., Earl, D. and Jeelani, S. Impact Response of Integrated Hollow Core Sandwich Composite Panels. Composites: Part A, 31, 2003, 761-72.

Hosur, M. V., Abdullah, M. and Jeelani, S. Manufacturing and Low-Velocity Impact Characterization of Hollow Integrated Core Sandwich Composites with Hybrid Face Sheets, Composite Structures, 65(1), 2004,103-115.

Scarponi, C., Briotti, G., Barboni, R., Marcone, A. and Iannone, M. Impact Testing on Composites and Sandwich Panels, Journal of Composite Materials, 30(17), 1996, 1873-1911.

Naik, N. K. and Nemani, B. Initiation of Damage in Composite Plates under Transverse Central Static Loading, Journal of Composite Structures, 52(2), 2001, 167-172.

Dweib, M. A., Hu, B., O’Donnell, A., Shenton, H. W. and Wool, R. P. All Natural Composite Sandwich Beams for Structural Applications, Composite Structures, 63, 2004,147-157.

Ahmed, K. S. and Vijayarangan, S. Tensile, Flexural and Interlaminar Shear Properties of Woven Jute and Jute Glass Fabric Reinforced Polyester Composites, Journal of Materials Processing Technology, 207(1-3), 2008, 330-335.

[45] Nangia, S. and Biswas, S. Jute Composite: Technology and Business Opportunities, Proceedings of International Conference on Advances in Composites at IISc and HAL, Bangolore, India, 2000, pp. 295-305.

[46] Kumar, A., Chandel, P. S. and Kumar, P. Experimental Study of Thin Sandwich Panel, Journal of Institution of Engineers, India, 87, 2006, 22-26.

Mines, R. A. W. and Jones, N. [1995]. Approximate Elastic Plastic Analysis of Static and Impact Behaviour of Polymer Composite Sandwich Beams, Journal of Composites, 26 (12), 1995, 803-814. 